\title{
3D Printed Splints an Innovative Method to Treat Temporomandibular J oint Pathology
}

\author{
ADINA SIRBU ${ }^{1}$, ROXANA BORDEA ${ }^{1 *}$, ONDINE LUCACIUㄴ, CLAUDIA BRAITORUㄴ, CAMELIA SZUHANEK², \\ RADU SEPTIMIU CAMPIAN ${ }^{1}$ \\ ${ }^{1}$ University of Medicine and Pharmacy luliu Hatieganu,Department of Oral Rehabilitation,Oral Health and Dental Practice \\ Management, 8 Victor Babes Str., 400010, Cluj Napoca, Romania \\ Victor Babes University of Medicine and Pharmacy, Faculty of Dentistry, 2 Eftimie Murgu Sq., 300041, Timisoara, Romania
}

\begin{abstract}
3D printing is a new technology with a particular resonance in dentistry which will become an important tool for all dental fields. In patients with TMJ pathology splints are used very often used to release the pain and to put the mandible in a centric relation. Conventional splints are made from acrylic designed by the dental technician with salt and pepper method or composite resins also designed by a dental technician on plaster model casts while 3D printed splints are computer designed so they can be preview resulting thus a much more accuracy in form and contact points.
\end{abstract}

Keywords: 3D printed splint, TMJ, orthodontics, facial asymmetries

Facial asymmetries are very common in an everyday dental practice but few studies have been conducted on the differential diagnostic between facial asymmetry caused by skeletal problems and one caused by a cervicofacial disfunctionality at the level of cervical vertebras or TMJ.

The temporomandibular joint (TMJ) is a synovial joint and include the condyle of the mandible, the articular eminence of the temporal bone, and the articular disc that is interposed between the two so it divides each joint into two cavities. TMJ it is a complex articulation because it is composed by two separete synovial joints, which have to function in a synergy. A fibrous capsule keeps the articulation stable. Centric relation or musculo-skeletal stable position is achieved when the condyle is situated in uppermost position in the temporal fossae with the disc between condyle and temporal bone. Mediallyand laterally, capsule stabilized TMJ. The medial capsule is not as strong as the lateral capsule, which is reinforced by the lateral temporo-mandibular ligament. Anteriorly and posteriorly, the capsule is loose to allow mandibular movement [1]. Temporomandibular joint problems begin early in life even though the symptoms are not present until the adultyears. It stars with condyle subluxation than the disc also become luxated. In growing children if the disc is not in the proper position growing of the condyle is less than in a normal articulation. This is why it is very important to treat disc displacement from early ages. Physical therapy in collaboration with dentistry provides an increasingly successful approach to longer lasting treatment [2]. Innervations of the temporomandibular joint are the auriculo-temporal, the masseteric and the posterior deep temporal nerves. They derive from the mandibular nerve after its passage through the oval foramen which is located medial to the TMJ articular eminence. The auriculotemporal nerve is a sensory nerve with autonomic nerve contribution. The nerve innervates the TMJ capsule, the tympanic membrane, the anterior surface of the cochlea, the skin lining the external auditory meatus, the upper part of the auricle, the tragus of the ear, the temporal region, the paratiroid gland, and the adjacent scalp above the auricle. The nerve also contributes to sensory innervation of the skin of the posterior part of the cheek. The masseteric nerve and the deep posterior temporal nerve branches are mainly motor nerves with sensory filaments distributed to the anterior part of TMJ capsule. The TMJ contains three types of nerve receptors Rufinni receptors, or Golgi when located in ligaments, Vater-Pacini and free nerve endings. The disc has no innervation. In joint with displacement disc(DD) pain will arise because of painful pressure on the innervated disc attachment. Orthopedic joint problems are by far the most common source of pain in the TM] [1].

A stable TMJ joint is defined as that in which both the right and left condyles sit in the uppermost position in the temporal fossae with the discs in place and closely related to the condyles and eminences while the upper and lower teeth are in maximum intercuspation with multiple equal contacts between tooth $[3,4]$.

Orthodontist wants to achieve and maintain a good occlusion, and this will notoccur if the patienthas resorbtion of the condyle [5].

Trpkova and coworkers have presented evidence that internal derangementin growing patient can be associated with condylar resorbtion which can caused skeletal asymmetries in children [6].

So when starting an orthodontic treatment were you want to align and level all the teeth it is very important to check the status of the TMJ. This is because disc displacement is found in an important number of patients [5].

Dr. Bernard J ankelson introduced the term Neuromuscular Dentistry to the dental profession in 1967. The masticatory system is a complex system composed of Teeth, Temporomandibular J oints, Muscle and Nerves. Without muscles the masticatory system is static and nonfunctional. Also malocclusion patterns seem not only to influence condylar position, but also the position of the glenoid fossa [7].

When treating the TMJ, we should address to the determining problem and to stop further degeneration of the joint [2].

Pain in the cervico-facial region is often associated with facial asymmetries. Facial asymmetries could be skeletal ,when one part of the face is bigger than the other part, or could be cervico-facial asymmetries due to cervical

* email: roxana.bordea@ymail.com 
malpositions ( $\mathrm{C} 1$ and $\mathrm{C2}$ ) which will cause different position of the temporal fossae and the TMJ .

Orthopedic instability is by far the most important cause of pain in the cervico-facial pain. Since pain in the cervical region could be generated by many pathological conditions we would focus in our study on pain caused by dysfunction at the level of cervical and Temporo-mandibular joint. Since there is a lack of criteria diagnostic we would like to find out if there is a relation between patient with cervico-facial pain, occlusal instability, TMJ dysfunction and rotation of cervical vertebra.

To establish a multidisciplinary approach of patient presented with pain in cervical region it is very important for a successful treatment.

Many TMJ headaches and referred pains of the neck and shoulders are caused by compression of the cervical joints. Treatment should address to overcome parafunctional habits by changing dysfunctional occlusion and kynetoterapy to restore mobility of the spine [2].

The treatment can be performed using splint therapy. Splints are made using acrylic or 3D printing materials. Acrylic resins can be obtained by different procedures: autopolymerization, photopolymerization, microwave polymerization, or thermopolymerization. Salt and pepper method is used to create splint made with the thermobaropolymerization of acrylate by saturate of polymer with monomer. The changes in the levels of humidity found in the oral cavity may produce changes in the splint property. The residual monomer found after the thermobaropolymerization determines irritation, mucosal inflammation, and an allergic reaction $[8,9]$.

The advancements in three-dimensional printing (3D) are also amplifying the interest in the use of versatile synthetic polymers for splints.Class II resins have been used for 3D printed splints, and in order to reduce the residual monomer, splints are immersed in ethanol [10-12].

The aim of this study was to evaluate the role of using two types of splints in treating TMJ pathology.

\section{Experimental part}

\section{Material and methods}

We included two case studies with TMJ pathology, in one we used a splint made by salt and pepper technique and in the other case a 3D printed splint.

After we made a precise diagnostic in which we excluded patient with neurological and ENT problems like Ehler Danlos syndrome, otitis, skeletal asymmetries, we included only asymmetries called cervical-facial asymmetries in which rotations of vertebra and orthodontic instability is the cause of cervical-facial pain.

Case nol is a 28 years old patient who was sent to our department with cervical-facial pain which lasted more than one year. We examined the patient with the protocol and we started treatment with splint therapy to relax the muscle and reposition the joints. Also physiotherapy was performed and after one month pain disappeared and we noticed improvement at TMJ function and the bite has change.
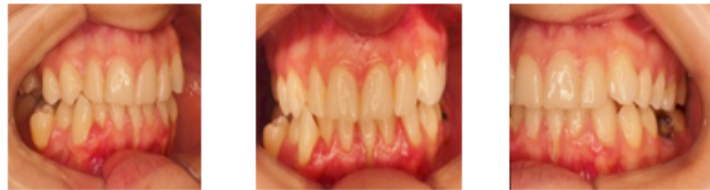

Fig. 1,2,3 Before conventional splint therapy

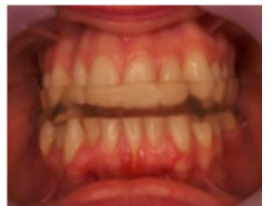

Fig. 4. With conventional splint
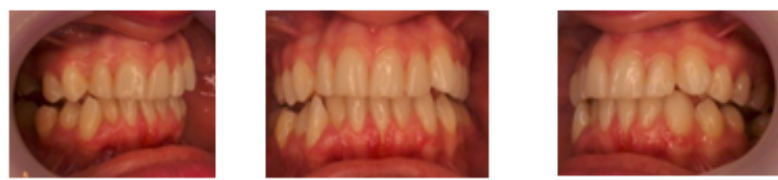

Fig. 5,6,7. After conventional splint therapy

Our orthodontic treatment protocol of the cervico-facial asymmetries is:

- Precise diagnostic using extra oral pictures, endoral pictures, CBCT, MRI, mounted models, clinical evolution by orthodontist, kynetotherapeut.

- Treatment plan will include splint therapy and kynetotherapy followed by orthodontic treatment.

- Muscle relaxation was obtained with an occlusal splint fabricated with corrected occlusal contacts.

-Restoration of posture of the head and neck with minimal muscle activity was done following Mariano Rocabado protocols.

-Corrected occlusal contact was provided with orthodontic/ prosthodontic therapy in order to minimize any muscular and postural dysfunctions.

-Research Diagnostic Criteria for TMD (RDC/TMD) guidelines were adopted to assess TMD patients.

Case no 2 represents a 32 years old patient who was referred to us with pain in the right temporomandibular
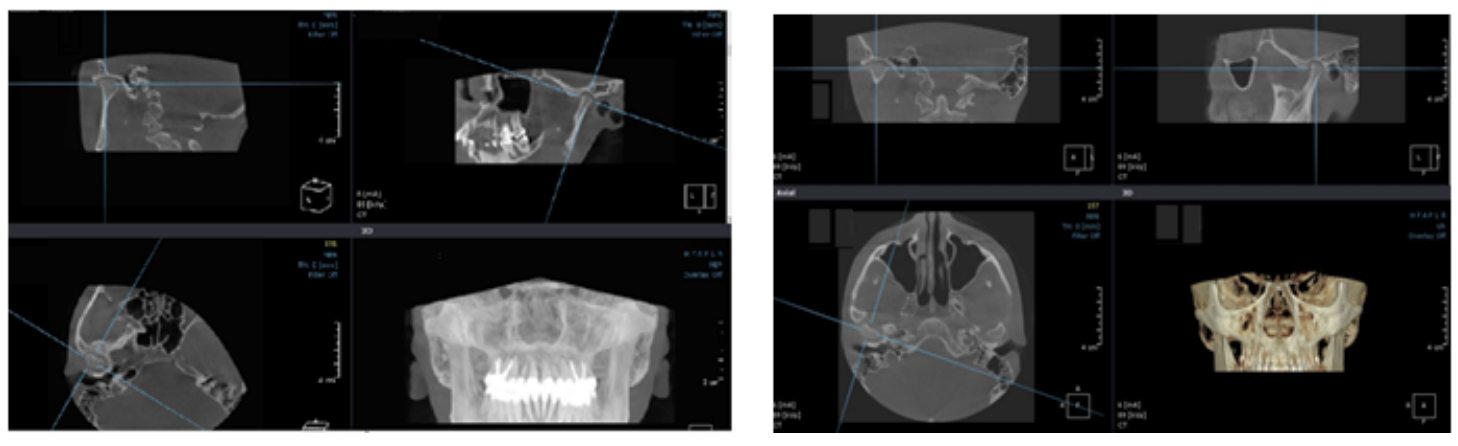

Fig. 8,9. CBCT of the right TMJ before and after
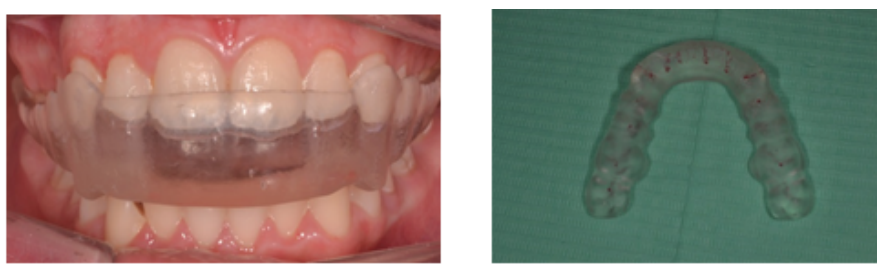

Fig. 10, 11. 3D Printed splint 
joint. For the differential diagnostic we used the same protocol as presented before.

Image before treatment shows active degenerative joint disease with cortical erosion. The erosive changes of the superior border of the right condyle is noted in the CBCT image before treatment and it appear to be slightly diminished with no evidence of increase changes as compared with the prior CBCT image after treatment. The radiographic features of the right condyle are suggestive of stable degenerative joint disease when compare the two CBCT images together.

Image after treatment shows that the right and left condyles are positioned almost in the center of their glenoid

Table 1

DIFERENTIAL DIAGNOSTIC CRITERIA FOR CERVICO-FACIAL ASYMETRIES

\begin{tabular}{|l|l|l|}
\hline & Case no l & Case no 2 \\
\hline $\begin{array}{l}\text { habitual } \\
\text { occlusion }\end{array}$ & CO \#CR & CO\#CR \\
\hline $\begin{array}{l}\text { ENT,Neurology } \\
\text { diagnostic }\end{array}$ & no pathology & no pathology \\
\hline asymmetries & yes & yes \\
\hline sounds:clicking & present & present \\
\hline $\begin{array}{l}\text { oclusion with } \\
\text { mounted models }\end{array}$ & class 2 & class 2 \\
\hline CBCT & $\begin{array}{l}\text { Condyle posteriorly } \\
\text { position with no } \\
\text { resorbtion }\end{array}$ & $\begin{array}{l}\text { Right condyle } \\
\text { with resorbtion } \\
\text { of cortical bone }\end{array}$ \\
\hline $\begin{array}{l}\text { general } \\
\text { hypermobility }\end{array}$ & no & no \\
\hline $\begin{array}{l}\text { facial } \\
\text { asymmetries }\end{array}$ & yes & yes \\
\hline cervical pain & yes & yes \\
\hline tmj pain & yes & yes \\
\hline facial pain & yes & \\
\hline and & yes & \\
\hline
\end{tabular}

fossa. There is mild flattening along the superior border of the left condyle, with no evidence of cortical irregularities.

\section{Results and discussions}

The result of the study suggests that patients with pain in cervical-facial region, facial and dental asymmetries should be treated by a multidisciplinary team which involves an orthodontist and a kynetotherapeut. Malocclusion should be address from the very beginning, splint and kynetotherapy should be started to relief the pain.

In case study no 1 patient had an unstable skeletal position at the TMJ, with a dysfunctional pattern, which caused cervical-facial pain. Due to unstable TMJ, ligament became hyper lax and dysfunctional TMJ movement caused a mandibular sift, disc displacement, asymmetries and pain. After splint and kynetotherapy, muscle became relaxed, and TMJ correct function was regained.
In case study no 2 because of unstable TMJ position, asymmetries, pain and condylar resorbtion was found. After 3D splint therapy a new CBCT was performed. The result showed new cortical bone formation at right TMJ and pain disappeared.

Vertical asymmetry showed a significant difference if we consider TMJ functional changes as opposed to transverse asymmetry [6]. This is similar with previous studies that have shown reduced vertical posterior facial and ramus height in adolescent TMD patients and in adult on lateral cephalograms [13-15].

\section{Conclusions}

Facial asymmetries and cervical-facial pain are very common among adults but can be found also in children. In adult facial asymmetries caused by unstable skeletal position can cause pain, disc displacement or condylar resorbtion but in children can cause differential growth at TMJ level and skeletal asymmetries which are more difficult to treat often needing orthognatic surgery. Precise diagnostic and protocols are needed to be used in treating pain and cervical-facial asymmetries.

Numerous physical therapy procedures are used with success in managing temporo-mandibular disorders TMD.

Facial asymmetry most of the times are misdiagnosed and because of this treatment usually didn't address to all of the problems that can be associated.

3D Splints made with printed materials show much more stability in the oral cavity and also have the advantages that can be reprinted if they are broken. Patients wearing this kind of 3D splint have a higher degree of satisfaction due to the fact that they are more aesthetic, lighter than the conventional ones and can be designed with more precise occlusal contact point. The time spent by the dentist to perform the occlusal adjustment is reduced due to their precision.

\section{References}

1.ISBERG, A., MARTIN DUNITZ PUBLISHERS, 2003, p 10-30

2.ROCABADO, M., JOHNSTON Jr, B. E., BLAKNEY, M. G. CRANI0,1,1,1982, p. 46-49.

3.IKEDA, K., TOPNOTCH KIKAKULTD, 2014.

4.MARTIN D.,COCCONI R., AM J ORTHOD DENTOFACIAL ORTHOP.

$141,1,2012$, p. 8-14

5.R.ANDREWGIRARDOT J R., GOAL-DIRECTED ORTHODONTICS, 2003. 6.MORA, J.,M.,B., ESCALONA. E., E., LABRUZZI, C., A., CARRERA, J., M., L., BALLESTEROS,E., J., C., ENRIQUE SOLANO REINILIO JIMENEZ, E., S., R., ROCABADO, M., CRANIO, 30, 2, 2012, p. 121-130.

7.TRPKOVA, B., MAJOR, P., NEBBE, B., PRASAD ,N., THE ANGLE ORTHODONTIST,70, No. 1, 2000, p. 81-88.

8.ICA, R. B., OZTURK, F., ATES, B., MALKOC, M. A., KELESTEMUR, Ü. THE ANGLE ORTHODONTIST, 84, 5, 2014, p. 862-867

9.DIBBETS J M, VAN DER WEELE LT, UILDRIKSAK.,J PEDOD., 9, 4,1985, P. 265-84.

10.ALIFUI-SEGBAYA， F.,BOWMAN, J.,WHITE, A.R.,VARMA, S.,LIESCHKE,G., GEORGE,R, ACTA BIOMATERIALIA ,78, 2018, p.64-63 11.STRINGERT, H. G. , F. W. WORMS. AM J ORTHOD ,89, 1986, p. 285297.

12. FERNANDEZ-GONZALEZ F., J, CANIGRAL A, LOPEZ-CABALLO JL, ET AL. J CLIN EXP DENT. 7, 2015,p.E320-E327.

13. BRANCO, L.,P., SANTIS, T.,O., ALFAYA T., A., J ORAL SCI. 55,1, 2013, p. 39-43.

14. MARTIN, D., ROZENCWEIG, S., MATE, A.,VALENZUELA, J., ORTHOD FR, 86, 2 , 2015, p. 125-149

15.F.M. SPEAR. QUINTESSENCE PUBLISHING CO, HANOVER PARK (IL).1997, P. $421-436$

Manuscript received: 11.02 .2018 